\title{
A democracia participativa na Assem- bléia Nacional Constituinte e na Constituição de 1988
}

\section{Participative democracy in the Constitu- tional Cational Assembly and the Constitution of 1988}

\author{
Jorge David Barrientos-Parra \\ Soraya Regina Gasparetto Lunardi²
}

Resumo: No presente artigo discorremos sobre as formas e os resultados relativos aos instrumentos de democracia participativa na Assembleia Nacional

1 Possui Graduação em Direito - Faculdades Metropolitanas Unidas, Mestrado em Direito pela Universidade de São Paulo e Doutorado em Direito - Université Catholique de Louvain, Bélgica. Visiting Assistant Professor in the Faculty of Applied Science and Engineering at the University of Toronto. Leciona a disciplina Implicações Éticas e Jurídicas das Influências da Tecnologia na Vida Humana, na Sociedade e na Biosfera no Programa de Mestrado em Direito da UNESP, Campus de Franca. Ministra também Direito Administrativo e Direito Constitucional no Curso de Administração Pública da UNESP, Campus de Araraquara. Líder do Grupo de Pesquisas (CNPq) Tecnologia, Direito e Sociedade.

2 Professora Livre Docente de Direito Constitucional, Direitos Fundamentais e Pesquisadora da UNESP. Líder de grupo de Pesquisa do CNPq: Desenvolvimento, políticas públicas e implementação dos direitos sociais no Brasil pós-1988. Doutora em Direito pela Pontifícia Universidade Católica de São Paulo (2006). Pós-doutorado pela Universidade Politécnica de Atenas (2007). Autora de mais de 100 estudos publicados em diversos países como: Estados Unidos, Itália, Grécia e Brasil. 
Constituinte e na Constituição de 1988. Para tanto examinamos os principais documentos que relatam essa participação. Trata-se de uma abordagem qualitativa, formalizada em duas estratégias: (i) revisão seletiva do material disponível na literatura brasileira e na base de dados do Congresso Nacional; (ii) estudo dos casos de projetos de lei decorrentes de iniciativa popular apresentados desde a criação da Constituição em 1988 e 2013 com a verificação de quantos Projetos de Lei propostos foram convertidos em Lei e como ocorre esse processo. Os principais resultados revelam uma aplicação muito pouco expressiva dos instrumentos de participação direta, com um total de sete Projetos de Lei apresentados onde apenas cinco foram convertidos em lei. Como principal conclusão afirmamos que os instrumentos de iniciativa popular de emendas à Constituição, o plebiscito e o referendo são instrumentos participativos quase desconhecidos dos eleitores brasileiros, cuja prática fortaleceria nossa jovem democracia. Apontamos de lege ferenda para a necessidade de uma reforma constitucional que retire os entraves que hoje dificultam o exercício da democracia participativa. Do ponto de vista metodológico, utilizamos o método histórico e dialético, numa perspectiva interdisciplinar, na qual dialogam o Direito Constitucional, a Sociologia Jurídica e a Ciência Política.

Palavras-chaves: Assembleia Nacional Constituinte; Constituição de 1988; Democracia Participativa; Soberania Popular.

Abstract: This article discusses the forms and results related to the instruments of participatory democracy in the National Constitutional Assembly and in the 1988 Constitution. For this purpose, the main documents that report this participation are 
examined. It is a qualitative approach, formalized in two strategies: (i) selective review of the material available in the Brazilian literature and in the Congress database (ii) case study of bills resulting from popular initiative presented since the creation of the Institution in 1988 and 2013 with the verification of how many proposed bills were converted into law and how this process occurs. The main results reveal a very insignificant application of the instruments of right judgment, with a total of 07 bills presented where only 05 were converted into law. As a main conclusion, the instruments of popular initiative to amend the Constitution, the plebiscite and the referendum are participatory instruments almost unknown to Brazilian voters, whose practice would strengthen our young democracy. We point lege ferenda to the need for a constitutional reform that removes the obstacles that currently hinder the exercise of participatory democracy. Legal and Political Science.

Keywords: Constitutional National Assembly; Constitution of 1988; Participative Democracy; Popular Sovereignty.

\section{Introdução ${ }^{3}$}

Decorridas três décadas da promulgação da Constituição de 1988 é relevante e oportuno relembrar e refletir sobre o processo de elaboração da atual Carta Magna brasileira.

Isso com o intuito de valorizar a riqueza da participação popular e do avanço que significou a inclusão de alguns instrumentos da democracia direta na recente história democrática brasileira. Como hipótese de trabalho defendemos

3 Os autores agradecem a leitura atenta e críticas fundamentadas da análise feita pelos pareceristas da Revista Brasileira de Estudos Políticos que possibilitaram o aperfeiçoamento do presente trabalho. 
neste artigo o aperfeiçoamento dessas técnicas democráticas o que exige uma reforma constitucional.

Na prática da democracia participativa o Brasil poderá encontrar o empuxo necessário para levar a sua democracia a patamares superiores, contudo estamos conscientes dos limites dos instrumentos de democracia direta representados pelo perigo da manipulação da mídia. Nesse sentido Jacques Ellul observa: "En définitive, toute propagande finit (même si l'on essaie de maintenir une confiance, une communion entre l'État et les gouvernés) par être une oeuvre de direction de la masse par le pouvoir". 4

Cientes disso o nosso olhar retrospectivo é, sobretudo, um método de trabalho para buscar entender como o sistema brasileiro (não) possibilita a democracia direta, uma forma de buscar entender as diferentes dimensões da democracia ${ }^{5}$ muitas vezes enfraquecida pelas manobras políticas das elites.

\section{A Assembleia Nacional Constituinte: convo- cação e instalação}

A convocação e o processo de elaboração da Constituição de 1988, a Constituição Cidadã, representativa e participativa na designação de Ulysses Guimarães, foi cercado de muita expectativa por toda a sociedade brasileira, afinal seria o marco de superação do regime autoritário no Brasil que começou com o golpe de Estado de 1964. A Assembléia Nacional Constituinte atraiu o olhar de todo o País reunindo as mais diversas correntes do pensamento nacional em torno dos grandes temas de interesse da sociedade. Depois de lon-

\footnotetext{
$4 \quad$ ELLUL, 1990, p. 264.

5 BROW, 2015. Aborda de maneira crítica o tema da democracia.
} 
gos anos de ditadura e repressão havia chegado o momento histórico da mudança. Nesse desiderato os partidos políticos de oposição à ditadura militar, os sindicatos, os estudantes, as mulheres, os negros, os índios, os movimentos populares, enfim a sociedade civil organizada recebeu com muito desejo de participação esse momento histórico.

Nesse sentido:

A Constituição, que modela, politicamente, a nação, que cria e ordena as instituições, capazes de garantir a felicidade geral e defender a paz, a dignidade, a integridade do país, também não é, unicamente, obra da cultura dos homens. Ela vem do mais profundo da consciência popular, nasce nos costumes, inspira-se nas ideias autonomistas da nação, surge com a própria independência. Tem, sobretudo, função ético-social e não poderia ser elaborada fora da vida e das exigências humanas. ${ }^{6}$

Havia uma imensa demanda represada por reconhecimento de direitos: individuais, sociais, políticos e econômicos. Muito embora a maioria da Assembleia fosse de parlamentares conservadores, esperava-se uma Constituição progressista que atendesse as demandas da população, sobretudo dos setores mais carentes.

A Assembleia Nacional Constituinte (ANC) foi convocada pela Emenda Constitucional $n^{\circ} 26$, de 27 de novembro de 1985. Essa emenda foi promulgada pelas Mesas da Câmara dos Deputados e do Senado Federal conjuntamente emendando o art. 49 da Constituição Federal de 1969, nestes termos: "Art. $1^{\circ}$ Os Membros da Câmara dos Deputados e do Senado Federal reunir-se-ão, unicameralmente, em Assembleia Nacional Constituinte, livre e soberana, no dia $1^{\circ}$ de fevereiro de 1987, na sede do Congresso Nacional".

6 Palavras do jurista José Duarte que, muito embora referidas à constituição de 1946, se adequam perfeitamente à Constituição de 1988. (DUARTE, 1947, p.37, v.1). 
Note-se que em lugar de se convocar uma autêntica Assembleia Nacional Constituinte convocou-se apenas um Congresso Constituinte. Em outras palavras, os eleitos para a Câmara dos Deputados e para o Senado Federal em 15 de novembro de 1986, 487 Deputados Federais e 49 Senadores - e mais 23 dos 25 Senadores eleitos em $1982^{7}$, num total de 559 parlamentares, oriundos de diversos grupos de pressão e de diversos horizontes ideológicos e partidários receberam os poderes constituintes originários ${ }^{8}$.

A ANC foi instalada pelo Presidente do Supremo Tribunal Federal, Ministro José Carlos Moreira Alves, em $1^{\circ}$ de fevereiro de 1987, o seu longo discurso não agradou à maioria dos políticos presentes à solenidade, pela ausência de referências mais explícitas à participação popular no processo que acarretou o fim do regime militar e desembocou na Constituinte. O texto do Informe JB citou as críticas feitas ao discurso pelo ex-senador - então vice-governador de São Paulo - Almino Afonso, que considerou excessiva a alusão à Constituição de 67, "outorgada pela ditadura", e lamentou a omissão do nome de Tancredo Neves, considerado "obrigatório" em pronunciamentos políticos associados à criação da chamada Nova República?.

$\mathrm{Na}$ segunda sessão foi eleito presidente o deputado Ulisses Guimarães com 425 votos, vencendo a candidatura alternativa de Lysâneas Maciel, que teve 69 votos. Ulysses

7 Foram eleitos em 1982 e participaram da Assembleia Nacional Constituinte de 1987-88 os seguintes Senadores: Afonso Sancho, Albano Franco, Carlos Alberto, Carlos Chiarelli, Guilherme Palmeira, Itamar Franco, João Castelo, João Lobo, João Meneses, Jorge Bornhausen, José Ignácio Ferreira, Leite Chaves, Leopoldo Peres, Luiz Freire, Marco Maciel, Marcondes Gadelha, Mauro Borges, Mendes Canale, Odacir Soares, Roberto Campos, Severo Gomes, Álvaro Dias, Hélio Gueirós, Marcelo Miranda, Fábio Lucena e Virgílio Távora.

8 SILVA, 2010, p. 25.

9 INFORME JB, 1987, p.06. 
encarnava o cidadão e o político que não se curvou diante da ditadura militar, por isso o elevado número de deputados que sufragaram o seu nome para presidir a Assembleia. Foi sem dúvida o político estrela da Constituinte. Depois de liderar os embates contra a ditadura soube dirigir com sabedoria e entusiasmo os trabalhos da Constituinte onde se destacou pelas suas qualidades de organizador e de negociador. Também soube dar o tom da importância histórica da ANC e transmitir a emoção daquele momento histórico unindo razão e coração nos discursos de abertura dos trabalhos e na sessão solene de encerramento em que conseguiu ser porta-voz das esperanças do povo brasileiro na construção de uma sociedade mais justa e democrática.

Colocou nos ombros dos Constituintes a responsabilidade histórica de redigir uma Constituição que fosse instrumento para instituir um Estado de Direito que respondesse aos anseios de justiça do povo brasileiro.

Os trabalhos foram concluídos em 5 de outubro de 1988. Ulysses Guimarães, em sessão solene a promulgou, admitindo a sua imperfeição, aliás, como toda obra humana: “A Constituição certamente não é perfeita. Ela própria o confessa ao admitir a reforma. Quanto a ela, discordar, sim. Divergir, sim. Descumprir, jamais. Afrontá-la, nunca. Não é a Constituição perfeita. Se fosse perfeita seria irreformável." Quanto à sua elaboração, ressaltou o seu processo inovador e a significativa participação popular:

Foi a audácia inovadora, a arquitetura da Constituinte, recusando anteprojeto forâneo ou de elaboração interna. O enorme esforço admissionado pelas 61.020 emendas, além de 122 emendas populares, algumas com mais de 1 milhão de assinaturas, que foram apresentadas, publicadas, distribuídas, relatadas e votadas no longo caminho das subcomissões até a redação final. A participação foi também pela presença, pois diariamente cerca de 10 mil postulantes franquearam livremente as 11 entradas do enorme complexo arquitetônico do Parlamento à procura dos gabinetes, comissões, 
galeria e salões. Há, portanto, representativo e oxigenado sopro de gente, de rua, de praça, de favela, de fábrica, de trabalhadores, de cozinheiras, de menores carentes, de índios, de posseiros, de empresários, de estudantes, de aposentados, de servidores civis e militares, atestando a contemporaneidade e autenticidade social do texto que ora passa a vigorar. ${ }^{10}$

E concluiu com as palavras que pronunciou no dia 2 de fevereiro de 1987 quando foi eleito presidente da ANC: “A Nação quer mudar. A Nação deve mudar. A Nação vai mudar. A Constituição pretende ser a voz, a letra, a vontade política da sociedade rumo à mudança. Que a promulgação seja o nosso grito. Mudar para vencer. Muda Brasil."

\section{A organização dos trabalhos, as comissões temáticas ${ }^{11}$, as subcomissões ${ }^{12}$ e a Comissão de Sistematização ${ }^{13}$}

A Assembleia Nacional Constituinte foi inovadora no sentido de não partir de um anteprojeto externo ou interno para balizar os trabalhos. Entretanto deve-se assinalar que o Anteprojeto Constitucional elaborado pela Comissão Provisória de Estudos Constitucionais ${ }^{14}$, instituída pelo Presi-

10 GUIMARÃES, 2006.

11 De acordo com o art. 13 do Regimento Interno da Assembleia Nacional Constituinte: "As Comissões incumbidas de elaborar o Projeto de Constituição em número de 8 (oito), serão integradas, cada uma, por 63 (sessenta e três) membros titulares e igual número de suplentes." (BRASIL, 1987b).

12 De acordo com a relação constante no art. 15 do Regimento Interno da Assembleia Nacional Constituinte. (BRASIL, 1987b).

13 “Haverá uma Comissão de Sistematização, integrada inicialmente por 49 (quarenta e nove) membros e igual número de suplentes, a qual terá sua composição complementada com os presidentes e os Relatores das demais Comissões". Art 13, $\$ 1^{\circ}$ do Regimento da ANC.

14 BRASIL, 1986. 
dente José Sarney ${ }^{15}$ e composta por cinquenta intelectuais ${ }^{16}$, liderados por Afonso Arinos de Melo Franco, serviu não somente de repositório de ideias engavetadas, mas foi uma fonte de inspiração para os constituintes e muitos trechos de seu texto passaram a fazer parte da letra do próprio texto constitucional.

A estrutura da ANC foi estabelecida no Regimento Interno (Resolução $n^{\circ} 2 / 87$ ) juntamente com o procedimento a ser seguido para a elaboração do texto constitucional. Foi estabelecida uma comissão de sistematização, e oito comissões temáticas, cada uma composta de três subcomissões.

De acordo com Oliveira ${ }^{17}$, os trabalhos desenvolveram-se em 7 etapas, as quais, por sua vez, desdobraram-se em 26 fases distintas, conforme se resume no quadro a seguir:

15 BRASIL, 1985.

16 Alberto Venâncio Filho, Alexandre José Barbosa Lima Sobrinho, Antônio Ermírio de Moraes, Bolívar Lamounier, Cândido Antônio Mendes de Almeida, Célio Borja (impedido de participar após ser indicado para o STF), Celso Monteiro Furtado, Cláudio Lacombe, Cláudio Pacheco, Clóvis Ferro Costa, Cristóvam Buarque, Edgard da Matta Machado, Eduardo Portella, Evaristo de Morais Filho, Fajardo Pereira Faria, Fernando Bastos D’Avila, Florisa Verucci, Gilberto Freyre, Gilberto de Ulhôa Canto, Guilhermino Cunha, Hélio Jaguaribe, Hélio Santos, Hilton Ribeiro da Rocha, João Pedro Gouveia Vieira, Joaquim Arruda Falcão Neto, Jorge Amado, Josaphat Marinho, José Afonso da Silva, José Alberto de Assumpção, José Francisco da Silva, José Paulo Sepúlveda Pertence, José do Rego Barros Meira de Araújo, José Saulo Ramos, Laerte Ramos Vieira, Luís Eulálio de Bueno Vidigal Filho, Luis Pinto Ferreira, Mário de Souza Martins, Mauro Santayana (secretário executivo da Comissão), Miguel Reale, Miguel Reale Junior, Ney Prado (secretário geral da Comissão), Odilon Ribeiro Coutinho, Orlando Magalhães de Carvalho, Paulo Brossard de Souza Pinto, Raphael de Almeida Magalhães, Raul Machado Horta, Rosah Russomano, Sérgio Franklin Quintella e Walter Barelli.

OLIVEIRA, 1987. 


\section{Quadro 1 - Quadro Resumo das Etapas e Fases da Assembleia Nacional Constituinte ${ }^{18}$}

\begin{tabular}{|c|c|}
\hline ETAPAS & FASES \\
\hline \multirow{2}{*}{ 1. Introdução } & Definição do Regimento Interno da ANC \\
\hline & Sugestões: Cidadãos, Constituinte e Entidades \\
\hline \multirow{3}{*}{$\begin{array}{l}\text { 2. Subcomissões Temá- } \\
\text { ticas }\end{array}$} & A: Anteprojeto do Relator \\
\hline & B: Emenda ao Anteprojeto do Relator \\
\hline & C: Anteprojeto da Subcomissão [AdaSub] \\
\hline \multirow{4}{*}{ 3. Comissões Temáticas } & E: Emenda ao AdaSub; na comissão \\
\hline & F: Substitutivo do Relator \\
\hline & G: Emenda ao Substitutivo \\
\hline & H: Anteprojeto da Comissão \\
\hline \multirow{8}{*}{$\begin{array}{l}\text { 4. Comissão de Sistema- } \\
\text { tização }\end{array}$} & I: Anteprojeto de Constituição \\
\hline & J: Emenda Mérito (CS) ao Anteprojeto \\
\hline & K: Emenda Adequação (CS) ao Anteprojeto \\
\hline & L: Projeto de Constituição \\
\hline & M: Emenda (1P) de Plenário e Populares \\
\hline & N: Substitutivo 1 do Relator \\
\hline & O: Emenda (ES) ao Substitutivo 1 \\
\hline & P: Substitutivo 2 do Relator \\
\hline \multirow{6}{*}{ 5. Plenário } & Q: Projeto A (início $1 .^{\circ}$ turno) \\
\hline & R: Ato das Disposições Transitórias \\
\hline & S: Emenda (2P) de Plenário \\
\hline & T: Projeto B (fim 1. ${ }^{\circ}$; início $2 .^{\circ}$ turno) \\
\hline & U: Emenda (2T) ao Projeto B \\
\hline & V: Projeto C (fim $2 .^{\circ}$ turno) \\
\hline \multirow{2}{*}{ 6. Comissão de Redação } & W: Proposta exclusivamente de redação \\
\hline & X: Projeto D - redação final \\
\hline 7. Conclusão & Y: Promulgação da Constituição de 1988 \\
\hline
\end{tabular}

18 Fonte: OLIVEIRA, 1987, p.11. 
De forma ilustrativa podemos dizer que essas etapas podem ser comparadas a um grande funil que foi se estreitando paulatinamente na medida em que se chegava mais perto dos trabalhos no Plenário.

Nessa fase foram ouvidas as mais diversas pessoas, representantes de entidades, públicas e privadas, movimentos sociais, sindicatos, associações e especialistas que deixaram por escrito milhares de sugestões às subcomissões. Além desse material as subcomissões receberam também milhares de sugestões dos parlamentares. A partir dessa gigantesca massa de propostas os relatores montaram seus anteprojetos, que somados tinham cerca de 685 artigos. Teve início então a fase de apresentação de emendas, foram apresentadas $14.920^{19}$. Os relatores aperfeiçoaram os anteprojetos para serem apresentados como substitutivos aos plenários das respectivas subcomissões.

Quanto à Comissão de Sistematização, podemos dizer que foi a mais importante coluna da estrutura da Assembleia Nacional Constituinte porque nela confluíam os anteprojetos das comissões temáticas, isto é, os textos fundamentais que constituiriam a matéria prima da redação do primeiro projeto de constituição.

De acordo com o Regimento da ANC (artigos 13 e 15) estava composta por 49 membros titulares e outros 49 suplentes, pelos presidentes e relatores das 8 comissões temáticas e pelos relatores das 24 subcomissões, somando, portanto, 89 membros. Entretanto para garantir as regras da representação proporcional foram adicionados quatro titulares permitindo assim que todos os partidos tivesse assento nela ${ }^{20}$.

19 JORNAL O GLOBO, 1987, p.6.

20 No dia nove de abril de 1987 se reuniu a Comissão com a finalidade de proceder à eleição para os cargos de Presidente e de Primeiro e Segundo 
Em 15 de julho de 1987, Ulysses Guimarães comunica o início da discussão do projeto em plenário. Nesse dia iniciou-se, também, o prazo de 30 dias para a apresentação de emendas dos Constituintes ${ }^{21}$ e de emendas populares subscritas por, no mínimo, 30.000 eleitores, em listas organizadas por no mínimo três entidades associativas. No final do prazo foram recebidas 20.791 emendas, das quais 122 emendas populares que foram defendidas no plenário da Comissão de sistematização de 26 de agosto a 4 de setembro de 1987.

\section{A participação popular na Assembléia Cons- tituinte}

Depois de anos de mobilização do povo exigindo a democratização e o fim do Estado de exceção, a Assembleia Nacional Constituinte de 1987-1988 possibilitou a participação popular como em nenhuma das constituições brasileiras anteriores.

Entre março de 1986 e julho de 1987, a Comissão de Constituição e Justiça do Senado Federal, antes mesmo da instalação da ANC, por meio do projeto "Diga Gente e Projeto Constituição" procurou mobilizar a sociedade colocando à disposição do povo, nas agências dos correios formulários para envio de sugestões aos constituintes. De acordo com o Jornal da Constituinte ${ }^{22}$, foram recebidas mais de 72.000

Vice-Presidentes. Foi eleito presidente o jurista Afonso Arinos (PFL-RJ) que obteve setenta e quatro votos, este designou para o cargo de Relator da Comissão o Constituinte Bernardo Cabral (PMDB-AM). Foi eleito PrimeiroVice-Presidente o Deputado Aluízio Campos (PMDB-PB) com 48 votos, e Segundo-Vice-Presidente o Deputado Brandão Monteiro (PDT - RJ) que recebeu 70 votos.

21 BRASIL, 1987. art. 23, § $1^{\circ}$..

22 JORNAL DA CONSTITUINTE, 2013, p.1. 
cartas, cujo efeito foi mais simbólico do que prático uma vez que o Regimento Interno da Constituinte não acolheu esta forma de participação popular ${ }^{23}$.

Concernente à participação popular o Regimento Interno da Assembleia Nacional Constituinte estabeleceu as seguintes possibilidades. Primeira, sugestões de entidades de acordo com o Art. 13, $\S 11^{24}$, dessa forma diversas entidades da sociedade civil, bem como Câmaras de Vereadores, Assembleias Legislativas e Tribunais apresentaram sugestões que foram encaminhadas às respectivas Comissões. Segunda, audiências públicas nas Subcomissões Temáticas, conforme $\mathrm{o}$ art. $14^{25}$. Terceira, emendas populares subscritas por, no mínimo 30.000 eleitores, de acordo com o Art. 2426. Quarta, defesa das emendas populares por um signatário perante a

23 O resultado da compilação das sugestões foi a criação da base de dados SAIC - Sistema de Apoio Informático à Constituinte. A SAIC reúne a íntegra das sugestões enviadas pelos cidadãos, além da identificação dos proponentes, tornando-se uma fonte importante para entender a realidade brasileira à época da Constituinte de 1987. A SAIC está disponível no portal do Senado Federal em conjunto com outras bases de dados históricas, para acessar as sugestões dos cidadãos, basta escolhê-la na lista e pesquisar pelo assunto desejado. Disponível em: http://www.senado.gov.br/atividade/ baseshist/bh.asp\#/. Acesso em: 16 abr. 2016.

24 “Às Assembleias Legislativas, Câmaras de Vereadores, e aos Tribunais, bem como às entidades representativas de segmentos da sociedade fica facultada a apresentação de sugestões, contendo matéria constitucional, que serão remetidas pelo Presidente da Assembleia às respectivas Comissões."

25 "As Subcomissões destinarão de 5 (cinco) a 8 (oito) reuniões para audiência de entidades representativas de segmentos da sociedade, devendo ainda, durante o prazo destinado aos seus trabalhos, receber as sugestões encaminhadas à Mesa ou à Comissão."

26 "Fica assegurada no prazo estabelecido no $\S 1^{\circ}$ do artigo anterior a apresentação de proposta de emenda ao Projeto de Constituição, desde que subscrita por 30.000 (trinta mil) ou mais eleitores brasileiros, em listas organizadas, por, no mínimo, 3 (três) entidades associativas, legalmente constituídas, que se responsabilizarão pela idoneidade das assinaturas, obedecidas as seguintes condições: [...]". Foram apresentadas 122 emendas deste tipo. 
Comissão de Sistematização de acordo com o Art. 24, VI ${ }^{27}$, dessa forma muitos cidadãos desprovidos do mandato constituinte puderam manifestar-se nessa importante comissão da ANC dando ampla projeção à emenda apresentada.

O Centro de Estudos e Acompanhamento da Constituinte da Universidade Nacional de Brasília indicou o número de 9.770 emendas. Já outra fonte, o Jornal da Constituinte, $n^{0}$ 63, na edição do dia da promulgação da Constituição, informou terem sido cerca de 12.000 propostas provenientes de 32.337 diferentes emendas subscritas pela população ${ }^{28}$.

As iniciativas para legalização de instrumentos de democracia direta demonstra que apesar de os partidos políticos seguirem sendo os protagonistas da relação entre Estado e Sociedade existe uma demanda da população pela atuação direta ${ }^{29}$, o que demonstra que estas agremiações vêm perdendo qualidade representativa, o que provoca distorções na redemocratização..$^{30}$ "A base social para a constituição e o exercício de uma gestão participativa e dialógica está na sociedade civil, a qual terá como alvo principal atuar nas estruturas sistêmicas do Estado." ${ }^{31}$

\section{Instrumentos de democracia participativa na Constituição de 1988}

Algumas dessas emendas foram inseridas no texto constitucional como a que estabelece os mecanismos de de-

27 “Na Comissão, poderá usar da palavra para discutir a proposta, pelo prazo de 20 (vinte) minutos, um de seus signatários, para esse fim indicado quando da apresentação da proposta."

28 ARAÚJO; AZEVEDO; BACKES, 2009, p. 26.

29 Sobre a legitimação do poder pela participação popular, ver Santin (2015, p. 251).

30 SANTANO; BLANCHET, 2015, p. 1005.

31 SANTIN, 2015, p. 251. 
mocracia direta: iniciativa popular ${ }^{32}$, plebiscito e referendo ${ }^{33}$. Outras formas de participação popular foram acolhidas na Constituição ${ }^{34}$ como a participação dos trabalhadores e empregadores nos colegiados dos órgãos públicos em que seus interesses profissionais ou previdenciários sejam objeto de discussão e deliberação $0^{35}$; foi consagrada também a eleição de um representante (nas empresas com mais de duzentos empregados), com a finalidade exclusiva de promover-lhes o entendimento com os empregadores ${ }^{36}$; bem como o preceito altamente benéfico para o controle social do gasto público de que, anualmente, as contas dos Municípios fiquem, durante sessenta dias, a disposição dos contribuintes para exame, apreciação e questionamento da legitimidade ${ }^{37}$ nesse mesmo diapasão foi inserida norma que legitima qualquer cidadão, partido político, associação ou sindicato para denunciar irregularidades ou ilegalidades perante o Tribunal de Contas da União ${ }^{38}$. Foram inseridas também várias disposições tendentes a democratizar a gestão da Saúde ${ }^{39}$, da Seguridade

32 "A iniciativa popular pode ser exercida pela apresentação à Câmara dos Deputados de projeto de lei subscrito por, no mínimo, um por cento do eleitorado nacional, distribuído pelo menos por cinco Estados, com não menos de três décimos por cento dos eleitores de cada um deles." (BRASIL, [2017], art. $61 \S 2^{\circ}$ ).

33 “Art. 14. A soberania popular será exercida pelo sufrágio universal e pelo voto direto e secreto, com valor igual para todos, e, nos termos da lei mediante: I - Plebiscito; II - Referendo; III - Iniciativa popular." (BRASIL, [2017]).

34 Tratando sobre a Participação popular e controle social em relação aos conselhos públicos ver: (CARDOSO; DE SOUZA, 2018).

35 BRASIL, [2017], art. 10.

36 BRASIL, [2017], art. 11.

37 BRASIL, [2017], art. 31, § $3^{\circ}$.

38 BRASIL, [2017], art. 74, § $2^{\circ}$.

39 BRASIL, [2017], art. 198, III. 
Social ${ }^{40}$, da Educação ${ }^{41}$, da Cultura ${ }^{42}$ e da Assistência Social ${ }^{43}$.

Na $15^{\text {a }}$ Reunião Ordinária da Comissão de Sistematização foram discutidas as emendas populares de números 21, 22 e 36 sobre Participação Popular. A mais inovadora delas era a de número 21 que foi defendida pelo Professor Dalmo de Abreu Dallari ${ }^{44}$. Ele preconizava a iniciativa popular no processo de emenda à Constituição mediante proposta subscrita por um número mínimo de eleitores igual a um por cento do eleitorado nacional. Sugeria também a iniciativa popular de lei no processo legislativo mediante proposta subscrita por setenta mil eleitores no mínimo.

Infelizmente, essa Emenda Popular não foi aprovada nos termos propostos. Afinal os Constituintes incluíram a iniciativa popular com as seguintes condicionantes: apresentação à Câmara dos Deputados de projeto de lei subscrito por, no mínimo, um por cento do eleitorado nacional, distribuído pelo menos por cinco Estados, com não menos de três décimos por cento dos eleitores de cada um deles ${ }^{45}$. Assim um projeto de iniciativa popular somente para ser apreciado pela Câmara dos Deputados, independentemente da sua aprovação, exige no mínimo 1.424 .678 assinaturas $^{46}$

40 “Compete ao Poder Público, nos termos da lei, organizar a seguridade social, com base nos seguintes objetivos: [...] caráter democrático e descentralizado da administração, mediante gestão quadripartite, com participação dos trabalhadores, dos empregadores, dos aposentados e do Governo nos órgãos colegiados." (BRASIL, [2017], art. 194, VII.

41 BRASIL, [2017], art. 206, VI.

42 BRASIL, [2017], art. 216, § $1^{\circ}$.

43 "Participação da população, por meio de organizações representativas, na formulação das políticas e no controle das ações em todos os níveis." (BRASIL, [2017], art. 204, II).

44 BRASIL, 1987.

45 Art. $61 \S 2^{\circ}$ da Constituição Federal de 1988. (BRASIL, [2017]). O total de eleitores hoje no Brasil é de 142.467.862 de acordo com o Tribunal Superior Eleitoral.

46 De acordo com o Tribunal Superior Eleitoral o total de eleitores hoje no 
de eleitores de cinco Estados diferentes, com não menos de 48.000 assinaturas em cada um deles. Considerando aumento vegetativo da população esses requisitos são a cada ano mais difíceis de serem atingidos.

Em razão disso, a iniciativa popular no Brasil não é, ainda, uma prática democrática, mas apenas uma exceção nos processos eleitorais. ${ }^{47}$

Na hipótese de apresentação de um projeto de iniciativa popular com fundamento no artigo $61 \S 2^{\circ}$, isto é, como instrumento de participação direta do cidadão nos atos de governo ${ }^{48}$ ou como instrumento de democracia participativa com fundamento no artigo $14^{49}$ (juntamente com o plebiscito e o referendo). Esse que deveria ser um exercício usual de manifestação do cidadão pelo voto direto e secreto, em virtude das barreiras colocadas é um ato político extraordinário que exige a mobilização do País inteiro para conseguir o colossal número de assinaturas requeridas. Isso somente é alcançado com o apoio de instituições com estrutura e recursos a nível nacional como a Ordem dos Advogados do Brasil e a Igreja Católica, ou com o envolvimento e suporte das estruturas de grandes sindicatos. Tudo isso frustra os anseios de participação do cidadão comum e o afasta da política.

Em pesquisa realizada foram levantados os projetos de lei apresentados por iniciativa popular de 1988 a 2013 A partir dos dados disponibilizados pelo órgão e com base nas informações disponibilizadas nos portais oficias da Câmara

Brasil é de 143.564.800. (BRASIL, [1988-2019]).

47 Uma crítica relevante contrapondo essa idéia, tratando sobre o desinteresse e a baixa participação da população brasileira em relação à política pode ser analisada pelo texto: $\mathrm{O}$ incremento da cidadania através do reforço da participação popular e a crescente judicialização da política. (BONATI; PEIXOTO, 2016).

48 SILVA, 2010, p. 530.

49 BRASIL, 1998. 
e do Senado. Foi identificado que os Projetos de Lei de iniciativa popular são denominados como "proposições adotadas". "O principal empecilho para que as proposições tramitem como projetos de lei de iniciativa popular é a dificuldade em se conferir a autenticidade das assinaturas, justificativa apresentada já no primeiro projeto desse tipo."

Com fundamento nessa justificativa "os deputados "adotam" a proposição, que, então passa a tramitar em seu nome." ${ }^{\prime \prime}$. Com base nessa pesquisa foram levantadas as seguintes propostas:

a) PL 2710/92 Esta proposição versou sobre a Criação do Fundo Nacional de Moradia Popular e o Conselho Nacional de Moradia. Patrocinado pelo Movimento Popular de Moradia, foi apresentado no dia 19/01/1992, sendo a primeira proposta legislativa com origem em iniciativa popular.

b) PL 4146/93 Este projeto teve como objetivo caracterizar como crime hediondo chacinas realizadas por esquadrões de morte. Este PL em questão foi resultado de iniciativa do Poder Executivo. A iniciativa popular adentra nesse projeto na forma de uma emenda sugerida por um deputado em resposta ao documento de iniciativa da novelista Glória Perez e com a assinatura de mais de um milhão e trezentas mil pessoas.

c) PL 1517/99 A proposição, apresentada na forma de projeto de lei, foi patrocinada pela Comissão Brasileira Justiça e Paz e pela Conferência Nacional dos Bispos do Brasil, com o apoio de mais de sessenta entidades, entres estas o Movimento Contra Corrupção Eleitoral (MCCE).

50 AUGUSTO, 2014, p. 129. 
d) PL 7053/06 PL que teve como finalidade a retirada do benefício relativo à fixação de pena para crime continuado quando se tratar de crime hediondo, tortura, genocídio; proíbe a apelação em liberdade para o condenado por esses crimes e por tráfico de drogas, bem como o indulto para o crime de tortura; e revoga o protesto por novo júri. Assinado por mais de um milhão e duzentos mil eleitores, teve como iniciador o "Movimento Gabriela Sou da Paz".

e) PL 1472/07 Este projeto foi iniciativa da Associação Comercial de São Paulo (ACSP), que o apresentou com o apoio de mais de um milhão e meio de assinaturas. A proposta, teve como objetivo a determinação de medidas que efetivassem o direito dos consumidores de serem informados acerca dos impostos que incidem sobre mercadoria e serviços, seja por meio de nota fiscal ou painel eletrônico visível no momento da compra.

f) PLP 518/09 Este projeto de lei complementar teve como iniciador o Movimento de Combate à Corrupção Eleitoral. A intenção do propositor era instituir a chamada "Ficha Limpa", obrigatória para os candidatos nas eleições em todos os níveis, aumentando para oito anos o período de inelegibilidade e suspendendo a exigência do trânsito em julgado nos casos em que a representação for julgada procedente pela Justiça Eleitoral.

g) PLP 321/2013 Este projeto de lei complementar teve como iniciadores o Conselho Nacional de Saúde e o Movimento Nacional em Defesa da Saúde Pública. A proposição foi apresentada com quase um milhão e novecentas mil assinaturas, com a finalidade de que ao menos dez por cento das receitas correntes 
brutas da União devessem ser destinadas ao financiamento da saúde.

Esse estudo nos permite deduzir que a Iniciativa Popular de lei ainda não se concretizou ${ }^{51}$, já que como não é possível verificar a autenticidade dos signatários das proposições prosseguem como outro tipo legislativo, onde um Congressista adota o projeto que se descaracteriza como lei de iniciativa popular. É questionável que o Poder Legislativo que estabeleceu tais exigências, não esteja preparado para verificar seu cumprimento. ${ }^{52}$

Esses projetos de lei também nos permitem inferir a sua valia uma vez que conseguiram incluir temas relevantes como propostas de moradia popular ou mesmo a Lei da Ficha Limpa que dificilmente seriam propostas pelos próprios congressistas. Além disso, a iniciativa popular fortalece a democracia já que promove a discussão, o posicionamento e a mobilização do povo em torno a diferentes temas.

Em decorrência dessas dificuldades em quase trinta anos de vigência da Constituição de 1988 somente quatro propostas de iniciativa popular se transformaram em lei ${ }^{53}$; o referendo foi utilizado somente uma vez, em 2005, ocasião em que o povo se pronunciou em relação a Estatuto do desarmamento; o plebiscito também foi utilizado somente uma

51 Uma crítica relevante sobre o processo legislativo pode ser encontrado no artigo de Cyrino (2016).

52 AUGUSTO, 2014, p. 136.

53 A saber, a que tornou crime hediondo o homicídio qualificado, Lei 8.930/94, a que estabeleceu a cassação de mandatos políticos por ter havido compra de votos, Lei 9.840/99, a que instituiu o Sistema Nacional de Habitação de Interesse Social - SNHIS e criou o Fundo Nacional de Habitação Popular - FNHIS, Lei 11.124/2005 e a denominada "Lei da ficha limpa", idealizada para barrar o acesso de políticos desonestos a cargos eletivos, Lei Complementar no 135, de 04 de junho de 2010. 
vez, em $1993^{54}$, ocasião em que o povo se pronunciou sobre a forma de governo ${ }^{55}$ (República ou Monarquia) e o sistema de governo ${ }^{56}$ (Presidencialismo ou Parlamentarismo) o que é muito pouco para uma democracia com mais de duzentos milhões de habitantes ${ }^{57}$ e de um colégio eleitoral de aproximadamente 150 milhões de eleitores.

Qual é a razão disso? Obviamente existe uma desconfiança da classe política em relação à participação popular ${ }^{58}$ e na raiz dessa desconfiança está o temor dos políticos de perder seu protagonismo frente ao povo, em consequência promove-se o clientelismo e obstaculiza-se a participação cidadã.

\subsection{Outros instrumentos:}

No dia 02 de maio de 2001, a Mesa da Câmara apresentou o projeto de resolução $n^{\circ} 151$, que criava a Comissão de Legislação Participativa (CLP), de caráter permanente. Esse dispositivo previsto no Regimento Interno da Câmara dos Deputados em seu artigo 254 permite a participação popular direta sendo um inovador instrumento:

Art. 254. A participação da sociedade civil poderá, ainda, ser exercida mediante o oferecimento de sugestões de iniciativa legis-

54 "No dia 7 de setembro de 1993 o eleitorado definirá, através de plebiscito, a forma (república ou monarquia constitucional) e o sistema de governo (parlamentarismo ou presidencialismo) que devem vigorar no País." Ato das Disposições Constitucionais Transitórias. (BRASIL, [2017], art. $2^{\circ}$ ).

55 A República recebeu 43.881.747, isto é, 66,26 \% dos votos e a Monarquia 6. 790.751, isto é, 10,25 \% dos votos. (BRASIL, [2018]).

56 O Presidencialismo recebeu 36. 685.630, o que representou 55,67\% dos votos e o Parlamentarismo 16.415.585, o que representou $24,91 \%$ dos votos.

57 De acordo com projeção do IBGE a população do Brasil é de 205.854.111. Disponível em: http://www.ibge.gov.br/apps/populacao/projecao/. Acesso em: 06 maio 2016.

58 BARRIENTOS-PARRA, 2011, p.10. 
lativa, de pareceres técnicos, de exposições e propostas oriundas de entidades científicas e culturais e de qualquer das entidades mencionadas na alínea $a$ do inciso XII do art. 32. ${ }^{59}$

Após se verificar o cumprimento dos requisitos formais, a sugestão então será distribuída pelo Presidente da Comissão para ser analisada por esta. Importante destacar que o regulamento estipula em dez sessões o prazo para a Comissão apresentar seu parecer. Inferindo pela admissibilidade, a sugestão passa a tramitar como sendo de autoria da Comissão, e tramitará como um PL comum.

Também foi criada no Senado, no dia 08/11/2001, uma Comissão de Direitos Humanos e de Legislação Participativa, inspirada no modelo já existente na Câmara, mediante proposta da senadora Marina Silva a fim de: “[...] contribuir para melhorar a imagem desgastada da Casa [...] estimular os grupos organizados a apresentarem sugestões legislativas, o que certamente contribuirá para democratizar a participação popular no processo legislativo." ${ }^{60}$ A autora justifica sua proposta justamente com base na subutilização do referendo do plebiscito e da iniciativa popular.

O surgimento destes institutos demonstra que ambos foram concebidos como alternativas para suplantar o embaraço que a legislação existente até então impunha à participação social no processo legislativo. ${ }^{61}$

\title{
4.2 Clientelismo VS participação cidadã
}

No Brasil, por necessidade, por desconhecimento dos meandros burocráticos, por falta de organização ou, simplesmente por comodidade, as pessoas recorrem aos políticos

\author{
59 BRASIL, 1989. \\ 60 BRASIL, 2001. \\ 61 AUGUSTO, 2014, p. 167.
}


para solucionarem todo tipo de problemas. Desde a poda de uma árvore, passando pela aceleração de um processo na administração; pedidos de bolsas de estudo, de atenção médica, de emprego, de assessoria jurídica, de moradia, ou melhorias no bairro. Na ausência do Estado e em virtude do péssimo funcionamento dos serviços públicos os políticos fazem a mediação entre o povo e a Administração Pública. Depois cobra-se a fatura em votos daquele que recebeu diretamente o benefício e de seus amigos e familiares.

Analisando o clientelismo no Rio de Janeiro, Eli Diniz comenta que nos problemas vivenciados por moradores dos subúrbios, como por exemplo, falta de iluminação ou de água se origina um processo complexo "incluindo uma verdadeira peregrinação às autoridades responsáveis, sem perspectiva de solução". Nessas circunstâncias a melhor saída é procurar um político para que encaminhe a demanda. Assim o vereador ou o deputado "agem como intermediários levando o problema a uma secretaria municipal, ao prefeito, enfim às autoridades competentes, encaminhando e negociando a medida pleiteada. A engrenagem funciona, portanto, através da mediação do político e não de forma impessoal, segundo padrões universalistas" 62 .

O clientelismo generalizado pelo Brasil afora, tem as suas raízes no coronelismo e este por sua vez na estrutura fundiária baseada no latifúndio como o demonstrou Victor Nunes Leal. O "coronelismo" é sobretudo um compromisso, uma troca de proveitos entre o poder público, progressivamente fortalecido, e a decadente influência social dos chefes locais, notadamente dos senhores de terras. ${ }^{63}$

Para Faoro "O coronelismo, o compadrazgo latino-americano, a clientela na Itália e na Sicília participam da estrutura

62 DINIZ, 1982, p. 123.

63 LEAL, 2012, p. 44. 
patrimonial. Peças de uma ampla máquina a visão do partido e do sistema estatal se perde no aproveitamento privado da coisa pública". ${ }^{64}$

Com a urbanização e a ampliação do ensino superior o clientelismo se diversificou e expandiu alcançando âmbitos como a filantropia e a caridade feita por igrejas e instituições assistenciais; abrangendo variados benefícios oferecidos por sindicatos de empregados e empregadores e também alcançou grande capilaridade através do atendimento realizado por profissionais liberais (médicos, advogados, dentistas, veterinários). Em um país em que as políticas públicas são apenas programas para viabilizar os chefes políticos de turno; e em que os direitos amiúde ficam somente no papel, o clientelismo se legitimou na busca da eficácia para sobreviver na política o que evidentemente passa por angariar votos para a próxima eleição.

Esse processo está associado às próprias concepções e práticas do que se entende por política. Evidentemente há um voto mais ideológico tanto à esquerda como à direita, contudo o padrão se mantém: eleitores procuram benefícios [materiais e imateriais] e políticos [de qualquer partido] procuram votos, analisando a legitimação de candidaturas através da filantropia, Coradini ${ }^{65}$ cita o discurso de um político rio-grandense: "Se alguém vota em um candidato, é porque ele precisa que aquele candidato venha a representá-lo. Então, alguma coisa ela vai precisar de que ele o ajude, e eu fiquei a inteira disposição dessas pessoas, para que no momento adequado, dentro dos limites, eu poderia ajudá-las".

Ora os políticos temem o enfraquecimento do seu poder social e das suas prerrogativas e privilégios se, por

64 FAORO, 2001, p. 718.

65 CORADINI, 2000, p. 130. 
hipótese, o povo passasse a promover diretamente às suas reivindicações e interesses e a encaminhar as suas propostas, iniciativas e projetos nas câmaras legislativas.

Entretanto a participação do povo implica no fortalecimento da autoridade dos parlamentares e no revigoramento das câmaras legislativas em todos os níveis da Federação e por consequência no robustecimento da própria democracia.

\section{De lege ferenda}

Afinal, esta visão que valoriza formas de democracia participativa acabou prevalecendo. O plebiscito, o referendo e a iniciativa popular foram incluídos na Constituição como possibilidades de exercício da soberania popular ${ }^{66}$, porém, infelizmente os Constituintes o fizeram de forma tímida, impondo-lhe elevadas barreiras.

Assim de lege ferenda é altamente desejável uma reforma constitucional no sentido de possibilitar ao povo a iniciativa de leis mediante a proposta subscrita por um número determinado de eleitores. Cinquenta mil eleitores como dispõe a Constituição Italiana ${ }^{67}$ nos parece um número razoável, uma vez que a análise quanto à constitucionalidade e à legalidade da proposta, bem como a análise do mérito remanescem com os parlamentares.

A constituição espanhola exige um mínimo de 500.000 assinaturas ${ }^{68}$. Em Portugal o direito de iniciativa legislativa

66 Art. 14 da Constituição Federal. O plebiscito, o referendo e a iniciativa popular foram regulamentados pela Lei $n^{\circ}$ 9.709/98 (BRASIL, 1998).

67 La Costituzione della Repubblica Italiana: “Art. 71: “A iniciativa das leis pertence ao Governo, a cada membro das Câmaras e aos órgãos e entidades aos quais seja conferida por lei constitucional. O povo exerce a iniciativa das leis, mediante proposta, por parte de pelo menos cinquenta mil eleitores, de um projeto redigido em artigos". (ITÁLIA, 2018, p.32.)

68 Constitución Española. "Artículo 87. Una ley orgánica regulará las formas de 
de cidadãos ${ }^{69}$ pode ser exercido por um mínimo de 35.000 cidadãos eleitores ${ }^{70}$. A Confederação Suíça com uma larga experiência em matéria de participação popular e de consultas ao povo estabeleceu que a iniciativa popular que objetive a reforma parcial da Constituição exige proposta assinada por no mínimo 100.000 eleitores $^{71}$, quando se trate simplesmente de um referendo facultativo a Constituição helvética exige somente o apoio de 50.000 eleitores $^{72}$. No âmbito da

ejercicio y requisitos de la iniciativa popular para la presentación de proposiciones de ley. En todo caso se exigirán no menos de 500.000 firmas acreditadas. No procederá dicha iniciativa en materias propias de ley orgánica, tributarias o de carácter internacional, ni en lo relativo a la prerrogativa de gracia." (ESPANHA, 1978, p.28).

69 Constituição da República Portuguesa. “Artigo 167. 1. A iniciativa da lei e do referendo compete aos Deputados, aos grupos parlamentares e ao Governo, e ainda, nos termos e condições estabelecidos na lei, a grupos de cidadãos eleitores, competindo a iniciativa da lei, no respeitante às regiões autónomas, às respectivas Assembleias Legislativas." (PORTUGAL, [2005], p. 54).

70 PORTUGAL, 2003, art. $6^{\circ}$..

71 Constitution fédérale de la Confédération suisse. "Art. 139 Initiative populaire tendant à la révision partielle de la Constitution 1.100000 citoyens et citoyennes ayant le droit de vote peuvent, dans un délai de 18 mois à compter de la publication officielle de leur initiative, demander la révision partielle de la Constitution. 2. Les initiatives populaires tendant à la révision partielle de la Constitution peuvent revêtir la forme d'une proposition conçue en termes généraux ou celle d'un projet rédigé. 3. Lorsqu'une initiative populaire ne respecte pas le principe de l'unité de la forme, celui de l'unité de la matière ou les règles impératives du droit international, l'Assemblée fédérale la déclare totalement ou partiellement nulle." (SUÍÇA, 2018).

72 Constitution fédérale de la Confédération suisse. "Art. 141 Référendum facultatif 1. Si 50000 citoyens et citoyennes ayant le droit de vote ou huit cantons le demandent dans les 100 jours à compter de la publication officielle de l'acte, sont soumis au vote du peuple:87 a. les lois fédérales; $b$. les lois fédérales déclarées urgentes dont la durée de validité dépasse un an; c. les arrêtés fédéraux, dans la mesure où la Constitution ou la loi le prévoient; d. les traités internationaux qui: 1. sont d'une durée indéterminée et ne sont pas dénonçables, 2. prévoient l'adhésion à une organisation internationale, 3.88 contiennent des dispositions importantes fixant des règles de droit ou dont la mise en œuvre exige l'adoption de lois fédérales." (SUÍÇA, 2018). 
União Europeia uma proposta de iniciativa popular exige um milhão de assinaturas ${ }^{73}$ de cidadãos provenientes de, no mínimo, 7 dos 28 Estados-Membros e obter em cada um desses 7 Estados-Membros um número mínimo de subscritores ${ }^{74}$.

Por tudo isso, seria um grande avanço para o amadurecimento e fortalecimento da democracia brasileira derrubar as barreiras que hoje tornam letra morta os instrumentos de democracia direta consagrados na Constituição Federal.

Sabemos que a democracia é vulnerável e que pode ser reduzida ou sofrer abusos de grupos ou de indivíduos, isto não pode ser justificativa para impedir que o povo se manifeste, nesse sentido e para evitar propostas de iniciativa popular demagógicas, contrárias aos princípios da República Federativa do Brasil, ou mesmo propostas frívolas ou vexatórias é de bom alvitre que a Lei defina suas modalidades e requisitos. Assim, por exemplo, em função da natureza da iniciativa o número de subscritores seria maior ou a coleta de assinaturas deveria ser feita em um prazo determinado, ou simplesmente certas matérias seriam insuscetíveis de serem objeto de deliberação mediante proposta de iniciativa popular.

Por último, já é tempo que a soberania popular possa ser exercida mediante um sistema que incorpore as modernas tecnologias digitais para a coleta das assinaturas necessárias, dessa forma teriam igual valor as assinaturas colhidas em papel e aquelas colhidas eletronicamente.

73 “Um milhão, pelo menos, de cidadãos da União, nacionais de um número significativo de Estados-Membros, pode tomar a iniciativa de convidar a Comissão Europeia a, no âmbito das suas atribuições, apresentar uma proposta adequada em matérias sobre as quais esses cidadãos considerem necessário um acto jurídico da União para aplicar os Tratados". (TRATADO da União Europeia, 2016, Art. 11², n. 4).

74 COMISSÃO EUROPÉIA, [2018]. 


\section{Conclusões}

O presente estudo demonstrou que a Constituição de 1988 é de todas as Constituições brasileiras a que mais recepcionou sugestões e ideias vindas diretamente do povo, mas por outro lado nosso olhar retrospectivo demonstra que o sistema brasileiro não possibilita a democracia direta de fato, mas apenas previu formalmente instrumentos de democracia direta que não tiveram uma aplicabilidade significativa.

Demonstramos ainda como o Regimento Interno que organizou os Constituintes em Comissões e Subcomissões também possibilitou centenas de audiências públicas que pulverizaram e enriqueceram os debates permitindo um debate plural no momento da elaboração do texto constitucional. Os Constituintes tiveram um profícuo diálogo com empresários, cientistas, associações de moradores, estudantes, garimpeiros, sindicalistas, mutuários, camponeses, operários, cadeirantes, sem-terra, artistas, domésticos e ONGs, nessa prática indicaram um caminho: ouvir o povo para construir uma democracia, mais justa, fraterna e solidária. Dessa forma demonstramos que de fato a Assembleia Nacional Constituinte de 1987-1988 possibilitou a participação de diferentes segmentos da população brasileira como em nenhuma das constituições brasileiras anteriores.

Por outro lado quando realizamos o levantamento de dados relativo à instrumentos de democracia participativa direta inseridas por emendas como: iniciativa popular, plebiscito e referendo temos um processo muito complexo e de difícil aplicabilidade não sendo possível sequer identificar a autenticidade dos signatários das proposições por falta de um sistema de controle de títulos de eleitores integrado. Como resultado é necessário que um Congressista adote o projeto o que descaracteriza essas leis como de iniciativa popular. 
Por entender que a participação do povo fortaleceria a autoridade dos parlamentares revigoraria as câmaras legislativas apresentamos, de lege ferenda, modelos internacionais mais simples e eficazes de participação democrática direta que permitiriam ao Brasil obter um melhor resultado de fortalecimento democrático.

Passados trinta anos, dessa experiência, relatadas todas as dificuldades de implementação conforme descrito nesse trabalho demonstramos que: somente quatro propostas de iniciativa popular se transformaram em lei; o referendo foi utilizado somente uma vez, assim como o plebiscito o que é muito pouco para uma democracia que aprovou mais de 5000 leis ao longo de 30 anos $^{75}$.

A razão nos parece ser uma desconfiança da classe política em relação à participação popular ${ }^{76} \mathrm{e}$ na raiz dessa desconfiança está o temor dos políticos de perder seu protagonismo frente ao povo, em consequência promove-se $o$ clientelismo e obstaculiza-se a participação cidadã.

\section{Referências}

ARAÚJO, José Cordeiro; AZEVEDO, Débora Bithiah de; BACKES, Ana Luiza (Org.). Audiências públicas na Assembleia Nacional Constituinte: a sociedade na tribuna. Brasília: Edições Câmara, 2009.

AUGUSTO, Luís Gustavo Henrique. Participação social no Legislativo Federal: um estudo da Comissão de Legislação Participativa (CLP), da Comissão de Direitos Humanos e Participação Legislativa (CDH) e da Iniciativa Popular de lei. 2014. Dissertação (Mestrado em Direito) - Escola de Direito, Fundação Getúlio Vargas, São Paulo, 2014. Disponível em:

75 LUNARDI; DIMOULIS, 2019, p. 215.

76 BARRIENTOS-PARRA, 2011, p. 10. 
http:/ /hdl.handle.net/10438/13706. Acesso em: 10 mar. 2018. BARRIENTOS-PARRA, Jorge (Dir.). L'Aube du Brésil. Paris: Société de Stratégi, 2011. (Agir, n. 47; Série Les Grands émergents).

BRASIL. Assembléia Nacional Constituinte (atas de comissões). Ata da reunião de instalação da comissão de sistematização. Brasília: Comissão de Sistematização, 1987a. Disponível em: http://www.senado.leg.br/publicacoes/anais/ constituinte/sistema.pdf. Acesso em: 3 maio 2016.

BRASIL. Assembléia Nacional Constituinte. Resolução n ${ }^{0}$ 3, de 1988. Altera o Regimento interno da Assembléia Nacional Constituinte. Brasília: Câmara dos Deputados, 1987b.

BRASIL. Câmara dos Deputados. Resolução n ${ }^{\circ}$ 17, de 1989. Aprova o Regimento Interno da Câmara dos Deputados. Brasília: Coordenação de Publicações, 1989. Disponível em: http:/ / bd.camara.leg.br/bd/handle/bdcamara/14117. Acesso em: 10 mar. 2018.

BRASIL. Comissão Provisória de Estudos Constitucionais. Suplemento especial ao $\mathrm{n}^{\circ}$ 185: anteprojeto constitucional, de 26 de setembro de 1986. Diário Oficial da União: seção I, Brasília, DF, n. 198, p.01-61, set. 1986. Suplemento Especial. BRASIL. [Constituição (1988)]. Constituição da República Federativa do Brasil de 1988. Brasília, DF: Presidência da República, [2017]. Disponível em: http://www.planalto. gov.br/ccivil_03/constituicao/constituicao.htm. Acesso em: 08 jan. 2017.

BRASIL. Decreto ${ }^{\circ}$ 91.450, de 18 de julho de 1985. Institui a Comissão Provisória de Estudos Constitucionais. Diário Oficial da União: seção 1, Brasília, DF, p. 10393, jul. 1985.

BRASIL. Lei n ${ }^{\circ}$ 9.709, de 18 de novembro de 1998. Regulamenta a execução do disposto nos incisos I, II e III do art. 14 da Constituição Federal. Diário Oficial da União, Brasília, DF, 19 nov. 1998. Disponível em: http:/ / www.planalto.gov.br/ ccivil_03/leis/19709.htm. Acesso em: 23 abr. 2017. 
BRASIL. Projeto de Resolução n. 56, de 2001. Diário do Senado Federal, $\mathrm{n}^{\circ}$ 157, p.28106, 09 nov. 2001. Disponível em: http://legis.senado.leg.br/diarios/BuscaDiario?tipDiario= $1 \&$ datDiario $=09 / 11 / 2001 \&$ paginaDireta=28107. Acesso em: 12 abr. 2014.

BRASIL. Tribunal Superior Eleitoral. Estatísticas do eleitorado: por sexo e faixa etária. Brasília: TSE, [1988-2019]. Disponível em: http://www.tse.jus.br/eleitor/estatisticas-de-eleitorado/estatistica-do-eleitorado-por-sexo-e-faixa-etaria. Acesso em: 3 maio 2016.

BRASIL. Tribunal Superior Eleitoral. Plebiscito de 1993. Brasília: TSE, [2018]. Disponível em: http://www.tse.jus.br/ eleicoes/ plebiscitos-e-referendos/plebiscito-de-1993. Acesso em: 23 abr. 2018.

BONATI, Débora; PEIXOTO, Fabiano Hartmann. O incremento da cidadania através do reforço da participação popular e a crescente judicialização da política. Revista Brasileira de Estudos Políticos, Belo Horizonte, n. 112, p. 109-146, jan./ jun. 2016.

BROWN, Wendy. Undoing the demos: neoliberalism's stealth revolution. Nova York: Zone Books, 2015.

COMISSÃO EUROPÉIA. Número mínimo de subscritores por Estado-Membro. [2018]. Disponível em: http:// ec.europa.eu/citizens-initiative/public/signatories. Acesso em: 03 mar. 2018.

CARDOSO, Henrique Ribeiro; DE SOUZA, Patrícia Verônica Nunes Carvalho Sobral. Participação popular e controle social: uma análise dos conselhos públicos à luz da teoria habermasiana. Revista Brasileira de Estudos Políticos, Belo Horizonte, n. 116, p. 309-349, jan./jun. 2018.

CORADINI, Odaci Luiz. Em nome de quem? recursos sociais no recrutamento de elites políticas. Rio de Janeiro: Relume Dumará, 2000. (Coleção Antropologia da Política).

CYRINO, André. Como se fazem as leis? democracia, grupos 
de interesse e controle de constitucionalidade. Revista Brasileira de Estudos Políticos, Belo Horizonte, n. 113, p. 51-99, jul./dez. 2016.

DINIZ. Eli. Voto e máquina política: patronagem e clientelismo no Rio de Janeiro. Rio de Janeiro: Paz e Terra, 1982.

DUARTE, José. A Constituição Brasileira de 1946, exegese dos textos à luz dos trabalhos da Assembleia Constituinte. Rio de Janeiro: Imprensa Nacional, 1947. 3 v.

ELLUL, Jacques. Propagandes. Paris: Economica, 1990.

ESPANHA. Constitución Española. Madrid: Agencia Estatal Boletín Oficial del Estado, 1978. Disponível em: https:// www.boe.es/legislacion/documentos/ConstitucionCASTELLANO.pdf. Acesso em: 03 fev. 2018.

FAORO, Raymundo. Os donos do poder: formação do patronato político brasileiro. 3. ed. rev. São Paulo: Globo, 2001. GUIMARÃES, Ulysses. Íntegra do discurso presidente da Assembléia Nacional Constituinte, Dr. Ulysses Guimarães. Brasília: Câmara dos Deputados, 2006. Disponível em: https://www2.camara.leg.br/camaranoticias/radio/ materias/CAMARA-E-HISTORIA/339277--INTEGRA-DO-DISCURSO-PRESIDENTE-DA-ASSEMBLEIA-NACIONAL-CONSTITUINTE,--DR.-ULISSES-GUIMARAES-\%2810-23\%29.html. Acesso em: 03 fev. 2018.

INFORME JB. Jornal do Brasil, Rio de Janeiro, 02 fev. 1987. Política, p.06.

ITÁLIA. Constituição da República Italiana. Costituzione Italiana Edizione in Lingua Portoghese. Roma: Senato della Repubblica, 2018. Disponível em: https://www.senato.it/ application/xmanager/projects/leg18/file/repository/ relazioni/libreria/novita/XVII/COST_PORTOGHESE.pdf. Acesso em: 03 fev. 2018.

JORNAL DA CONSTITUINTE. Brasília: Câmara dos Deputados, 29 out. -8 nov. 2013. 
JORNAL O GLOBO. Rio de Janeiro: Grupo Globo, 27 dez. 1987.

LEAL, Victor Nunes. Coronelismo, enxada e voto: o município e o regime representativo no Brasil. 7. ed. São Paulo: Companhia das Letras, 2012.

LUNARDI, Soraya Gasparetto; DIMOULIS, Dimitri. A Constituição na sala de espelhos. Revista dos Tribunais, São Paulo, n. 1000, ano 108, p. 215-227, fev. 2019.

OLIVEIRA, Mauro Márcio. Fontes de informações sobre a Assembleia Nacional Constituinte de 1987: quais são, onde buscá-las e como usá-las. Brasília: Senado Federal, Subsecretaria de Edições Técnicas, 1993.

PORTUGAL. Constituição da República Portuguesa: VII Revisão Constitucional [2005]. Lisboa: Assembleia da República, [2005]. Disponível em: https://www.parlamento. pt/Legislacao/Documents/constpt2005.pdf. Acesso em: 03 fev. 2018.

PORTUGAL. Lei n. ${ }^{\circ}$ 17/2003, de 4 de junho de 2003. Iniciativa legislativa de cidadãos. Diário da República: I série-A, Lisboa, n.129, p.3349, 4 jun. 2003. Disponível em: https:// dre.pt/application/file/a/553362. Acesso em: 03 fev. 2018. SANTANO, Ana Claudia; BLANCHET, Luiz Alberto. 30 anos de redemocratização e o desenvolvimento da participação política em tempos de democracia: o caso do Decreto $\mathrm{n}^{\mathrm{o}}$ 8.243/ 2014 e a sua rejeição pelo Congresso Nacional. Revista Brasileira de Estudos Constitucionais, Belo Horizonte, v. 9, n. 32, p. 999-1022, maio/ago. 2015.

SANTIN, Janaína Rigo. Estado, Sociedade Civil e Legitimação do Poder. Revista Brasileira de Estudos Políticos, Belo Horizonte, n. 111, p. 247-274, jul./ dez. 2015.

SILVA, José Afonso da. Comentário contextual à Constituição. 7.ed. São Paulo: Malheiros, 2010.

SUÍÇA. Constitution Fédérale de la Confédération Suisse 
du 18 avril 1999. Berne: Le Conseil fédéral, 23 sept. 2018. Disponível em: https://www.admin.ch/opc/fr/classified-compilation/19995395/. Acesso em: 03 fev. 2018.

TRATADO da União Européia (versão consolidada). Jornal Oficial da União Europeia, 07 jun. 2016. Disponível em: https:/ / eur-lex.europa.eu/resource.html?uri=cellar:9e8d52e12c70-11e6-b497-01aa75ed71a1.0019.01/DOC_2\&format=PDF. Acesso em: 03 fev. 2018.

Os autores do artigo participaram de forma conjunta de todas as fases (concepção e desenho da pesquisa, coleta, análise e interpretação dos dados e redação do texto final) de sua elaboração e assumem a corresponsabilidade acadêmica e ética da integralidade do conteúdo. (Texto a partir de declaração assinada pelos autores)

Recebido em 21/01/2019

Aprovado em 21/01/2020

Jorge David Barrientos-Parra

E-mail: barrientos.parra@unesp.br

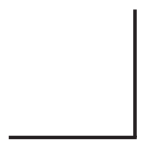

Soraya Regina Gasparetto Lunardi

E-mail: soraya.gasparetto@unesp.br 